\title{
SEOM Guidelines 2015: a new era in the collaboration with the Spanish Cancer Research Cooperative Groups
}

\author{
C. A. Rodriguez ${ }^{1} \cdot$ M. Martín ${ }^{2}$
}

Received: 9 December 2015/Accepted: 10 December 2015/Published online: 17 December 2015

(C) Federación de Sociedades Españolas de Oncología (FESEO) 2015

SEOM clinical guidelines were born in 2010 as a perceived need by the Spanish oncologists, that required clinical practice documents tailored to the peculiarities of the spanish healthcare system. Since then, in the successive annual editions, numerous guidelines have been published focusing on the diagnosis and therapeutic management of the most prevalent malignancies and also in relation to supportive care and symptom control. As we have remarked on previous occasions, there is no doubt of the need of editing local guides about the medical treatment of cancer. Sometimes it could be considered unnecessary because many other international guidelines are also available. However, it is well known that the particularities of patient care varies depending on numerous factors, such as health care setting, geographic area, access to new drugs, insurance coverage, and local treatment protocols [1]. A recent comprehensive survey conducted by SEOM has detected disparities in the treatment and services provided to the patients depending on the geographic area or the center considered. This report will be published during 2016 and reveals the need of national guidelines as a way to reduce disparities. This fact has been taken into account

Member of the Executive Board of the Spanish Society of Medical Oncology (SEOM) - C. A. Rodriguez.

President of the Spanish Society of Medical Oncology (SEOM)-M. Martín.

C. A. Rodriguez

crodriguez@oncologiasalamanca.org

1 Department of Medical Oncology, Hospital Universitario de Salamanca-IBSAL, Salamanca, Spain

2 Medical Oncology Department, Hospital General Universitario Gregorio Marañon, Madrid, Spain by the SEOM organization, which has positioned itself unequivocally in favor of equity of access to treatments for all patients along our country.

However, on the other hand, the Spanish Cooperative Research Groups, working under the umbrella of SEOM, have played a relevant role in the generalization of standards of care of many cancers. In the last decade, these groups have reached a level of scientific production and quality of research that has positioned themselves as international leaders in most fields of oncology. Therefore, SEOM considered necessary in the present edition of their clinical guidelines to establish an alliance with the major research groups as a guarantee of quality of the content and selection of authors of the manuscripts. The guides have been written by recognized national experts, selected by the research groups themselves, with common editorial standards and same criteria for evidence-based information. These premises provide to the present edition of the guides an added value to place them on a par with other international guidelines.

In this issue, two guides on management of hereditary colorectal (CRC) cancer, and hereditary breast and ovarian cancer have been incorporated. In the first one, GuillenPonce et al., describes genetics, current diagnosis and management of hereditary CRC syndromes pointing to a multidisciplinary approach to achieve the best results in patients and family outcomes [2]. In the breast and ovarian hereditary guide, Llort et al., describes deeply main recommendations related with criteria for BRCA genetic testing, surveillance and strategies for early detection in mutation carriers, riskreduction surgery, chemoprevention, and new treatment strategies in BRCA carriers. In addition, they review other hereditary breast cancer syndromes [3].

Two guides previously published about management of breast cancer have been updated. As authors remark, breast 
cancer is still a major public health problem. Despite remarkable advances in early diagnosis and treatment, one in three women may have metastases since diagnosis, and is the leading cancer-related cause of death between Spanish women. Better understanding of prognostic and predictive factors allows us to select the most appropriate adjuvant therapy in each patient. In these guidelines, the experts summarize current evidence for the medical management of both early-stage and metastatic breast cancer $[4,5]$

There is no doubt that malignant melanoma is one of the malignancies in which in the last years advances in diagnosis and treatment have changed in a dramatic way the management of the disease. The new systemic treatment strategies based on mutational analysis of the tumor, and of course the new immunotherapy have been deeply reviewed by the authors of the guide [6].

In the metastatic colorectal guide, Aranda et al., make a remark in colorectal cancer which is still the second leading cause of cancer dead in Spain; and about half the patients will eventually develop distant metastases. However, treatment options are expanding and prognosis has improved over the last decades. Management of advanced CRC is discussed from a multidisciplinary point of view, to select the most appropriate therapy, and designing a customized treatment plan [7]. It is well known that gastric cancer is a major health problem is Spain. The new guidelines reinforce the evidences that gastroesophageal junction tumors and gastric cancer should be considered as two independent entities with a different prognosis and treatment approach. The role of neoadjuvant and adjuvant therapy is revised, as well as, treatment for stage IV tumors, with special emphasis in randomized phase III trials with overall survival improvement [8]. To complete the information about the management of digestive tumors, we have also incorporated guidelines about hepatocellular carcinoma and biliary tract cancers $[9,10]$.

García-Campelo et al., remind us that lung cancer is the most common cancer worldwide as well as the leading cause of cancer-related deaths, and non-small cell lung cancer (NSCLC) accounts for up to $85 \%$ of all lung cancers. Multiple advances in the staging, diagnostic procedures, therapeutic options, as well as molecular knowledge have been achieved during the past years. All these major advances have been included in the new version of the SEOM guidelines [11].

Authors of the cervical cancer guidelines emphasize that although screening programs have led to a relevant reduction in the incidence and mortality due to this disease in developed countries, it is still an important cause of mortality in undeveloped countries and clinical stage is still the most relevant prognostic factor. A review of primary treatment in early and locally advanced stages is performed as well as strategies in recurrent or metastatic disease with the combination of chemotherapy plus antiangiogenic drugs [12]. Finally an updated version of two previously published guides on Follicular non-Hodgkin's lymphoma and Hodgkin's lymphoma have been incorporated, to provide to medical oncologist new evidence in the management of these entities [13, 14].

Acknowledgments Members of the executive board of the SEOM: Garrido P, Martiin M, Aparicio J, Baron FJ, Garcia-Campelo R, Garcia-Carbonero R, Lianes P, Llombart A, Muñoz M, Rivera F, Rodríguez CA and Virizuela JA. Members of the executive boards of the Spanish Cancer Cooperative Research Groups (SOLTI, GEICAM, TTD, GEMCAD, GEICO, GEM, GECP, GOTEL) and the Hereditary Cancer Working Group of the SEOM.

\section{References}

1. Rodriguez CA. Cruz-Hernández JJ. SEOM guidelines 2013: a response to the needs of Spanish oncologists. Clin Transl Oncol. 2013:15(12):975-6.

2. Guillén-Ponce C, Serrano R, Sánchez-Heras AB, Teulé A, Chirivella I, Martín $\mathrm{T}$, et al. Clinical guideline seom: hereditary colorectal cancer. Clin Transl Oncol. 2015;17(12). doi:10.1007/s12094-015-1439-z.

3. Llort G, Chirivella I, Morales R, Serrano R, Beatriz Sanchez A, Teulé A, et al. SEOM clinical guidelines in Hereditary Breast and ovarian cancer. Clin Transl Oncol. 2015;17(12). doi:10.1007/s12094-015-1435-3.

4. Garcia-Saenz JA, Bermejo B, Estevez LG, Palomo AG, Gonzalez-Farre X, Margeli M, et al. SEOM clinical guidelines in early-stage breast cancer 2015. Clin Transl Oncol. 2015;17(12). doi:10.1007/s12094-015-1427-3.

5. Gavilá J, Lopez-Tarruella S, Saura C, Muñoz M, Oliveira M, De la Cruz-Merino $\mathrm{L}$, et al. SEOM clinical guidelines in metastatic breast cancer 2015. Clin Transl Oncol. 2015;17(12). doi:10.1007/s12094-015-1476-7.

6. Berrocal A, Arance A, Espinosa E, Castaño AG, Cao MG, Larriba JLG, et al. SEOM guidelines for the management of Malignant Melanoma 2015. Clin Transl Oncol. 2015;17(12). doi:10.1007/s12094-015-1450-4.

7. Aranda E, Aparicio J, Alonso V, Garcia-Albeniz X, Garcia-Alfonso P, Salazar $\mathrm{R}$, et al. SEOM clinical guidelines for diagnosis and treatment of metastatic colorectal cancer 2015. Clin Transl Oncol. 2015;17(12). doi:10.1007/s12094 015-1434-4

8. Martin-Richard M, Custodio A, García-Girón C, Grávalos C, Gomez C, Jimenez-Fonseca $\mathrm{P}$, et al. Seom guidelines for the treatment of gastric cancer 2015. Clin Transl Oncol. 2015;17(12). doi:10.1007/s12094-015-1456-y.

9. Benavides M, Antón A, Gallego J, Gómez MA, Jiménez-Gordo A, La Casta A, et al. Biliary tract cancers: SEOM clinical guidelines. Clin Transl Oncol. 2015;17(12). doi:10.1007/s12094-015-1436-2.

10. Sastre J, Díaz-Beveridge R, García-Foncillas J, Guardeño R, López C, Pazo R, et al. Clinical guideline SEOM: hepatocellular carcinoma. Clin Transl Oncol 2015;17(12). doi:10.1007/s12094-015-1451-3.

11. García-Campelo R, Bernabé R, Cobo M, Corral J, Coves J, Dómine M, et al SEOM guidelines for the treatment of non-small cell lung cancer (NSCLC) 2015. Clin Transl Oncol. 2015;17(12). doi:10.1007/s12094-015-1455-Z.

12. Oaknin A, Rubio MJ, Redondo A, De Juan A, Cueva Bañuelos JF, Gil-Martin M, et al. SEOM guidelines for cervical cancer. Clin Transl Oncol. 2015;17(12). doi: 10.1007/s12094-015-1452-2.

13. Provencio Pulla M, Alfaro Lizaso J, de la Cruz Merino L, Gumá i Padró J, Quero Blanco C, Gómez Codina J, et al. SEOM clinical guidelines for the treatment of follicular non-Hodgkin's lymphoma. Clin Transl Oncol. 2015;17(12). doi:10.1007/s12094-015-1437-1.

14. Rueda Domínguez A, Alfaro Lizaso J, de la Cruz Merino L, Gumá i Padró J, Quero Blanco C, Gómez Codina J, et al. SEOM clinical guidelines for the treatment of Hodgkin's lymphoma. Clin Transl Oncol. 2015;17(12). doi:10. 1007/s12094-015-1429-1. 